\title{
Klinik Deneyim Yaşayan Hemşirelik Öğrencilerinin Duygu Düzenleme Güçlüklerinin İncelenmesi
}

\section{An Investigation of Emotional Regulation Difficulties of Nursing Students with Clinical Experience}

\author{
${ }^{1}$ Nihan ALTAN SARIKAYA, ${ }^{2}$ Çisem TAŞ, ${ }^{2}$ Nisa AKGÜN \\ ${ }^{1}$ Trakya Üniversitesi Sağlık Bilimleri Fakültesi, Ruh Sağlığı ve Psikiyatri Hemşireliği Anabilim Dalı, Edirne, Türkiye \\ ${ }^{2}$ Trakya Üniversitesi Sağlık Bilimleri Fakültesi, Hemşirelik Bölümü, Edirne, Türkiye
}

Nihan Altan Sarıkaya: https://orcid.org/0000-0002-3678-6186

Cisem Taş: https://orcid.org/0000-0002-8496-1559

Nisa Akgün: https://orcid.org/0000-0003-3183-9178

\begin{abstract}
ÖZ
Amaç: Hemşirelik bölümü öğrencileri üniversite eğitimleri sırasında sosyal, kişisel, maddi sorunlar yaşamakla beraber akademik ve klinik deneyimleri sırasında da çeşitli duygusal zorluklar yaşamaktadırlar. Araştırmanın amac klinik deneyim yaşayan hemşirelik öğrencilerinin duygusal zorlanmalarının nedenleri ve duygu düzenleme güçlüklerinin çeşitli değişskenler açısından incelenmesidir.

Materyal ve Metot: Araştırma bir devlet üniversitesinin hemşirelik bölümünün 2. 3. ve 4. sınıfinda okuyan 342 öğrencisi ile tanımlayıcı tipte yürütülmüştür.

Bulgular: Klinik deneyim sırasında öğrencilerin en fazla profesyonel hemşirelik becerisi eksikliğine dayalı yetersizlik hissi yaşadıklarında ve meslek grupları arasında profesyonel olmayan davranışları gözlemlemediklerinde duygusal zorlanma yaşadıkları saptanmıştır. Öğrencilerin fiziksel hastalık, ruhsal hastalık, psikolojik yardım alma, yaşamında önemli bir olayla karşılaşma durumları ve ailenin yaklaşımı ile Duygu Düzenleme Güçlüğü Ölçeği toplam puan ortalaması arasında anlamlı bir fark saptanmıştır $(\mathrm{p}<0,05)$.

Sonuç: Öğrencilerin duygusal zorlanmalar yaşadıkları ve cinsiyet, fiziksel hastalık, ruhsal hastalık, psikolojik yardım alma, yaşamında önemli bir olayla karşılaşma durumları ve ailenin yaklaşımı gibi değişkenlerden etkilendiğ belirlenmiştir.
\end{abstract}

Anahtar Kelimeler: Duygu düzenleme, duygusal zorlanma, klinik deneyim, öğrenci hemşire

\begin{abstract}
Objective: Nursing students experience various emotional difficulties during their academic and clinical experiences as well as social, personal and financial problems during their university education. The purpose of this study is to examine the causes of emotional difficulties and emotional difficulties of nursing students with clinical experience in terms of various variables.
\end{abstract}

Materials and Methods: The study was conducted with descriptive features with 342 students studying in the 2nd, 3 rd and 4 th grades of the nursing department of a public university.

Results: It was determined that during the clinical experience, the students experienced emotional difficulties when they experienced the inadequacy based on the lack of professional nursing skills and they did not observe nonprofessional behaviors among professional groups. A significant difference was found between the students' physical illness, mental illness, psychological help, situations of encountering an important event in their life, and the family's approach and the total score average of the Difficulties in Emotion Regulation Scale $(p<0,05)$.

Conclusion: It was determined that students experienced emotional difficulties and were affected by variables such as gender, physical illness, mental illness, psychological help, situations of encountering an important event in their life, and family approach.

Keywords: Emotion regulation, emotional strain, clinical experience, student nurse

\footnotetext{
Sorumlu Yazar / Corresponding Author:

Nihan Altan Sarıkaya

Trakya Üniversitesi, Sağlık Bilimleri Fakültesi, Ruh Sağlığı ve

Psikiyatri Hemşireliği Anabilim Dalı, Edirne

Tel: +90(284)2133042 (2131)

E-mail: nihanaltan85@gmail.com
}

\section{Yayın Bilgisi / Article Info:}

Gönderi Tarihi/ Received: 14/12/2020

Kabul Tarihi/ Accepted: 22/03/2021

Online Yayın Tarihi/ Published: 05/06/2021

Atıf / Cited: Altan Sarıkaya N ve ark. Klinik Deneyim Yaşayan Hemşirelik Öğrencilerinin Duygu Düzenleme Güçlüklerinin İncelenmesi. Online Türk Sağlık Bilimleri Dergisi 2021;6(2):191-200. doi: 10.26453/otjhs.840812 


\section{GíRiş}

Hemşirelik eğitiminin klinik uygulama kısmı, öğrenilen teorik bilgilerin klinik uygulama sırasında edinilen kazanımlarla birleşmesine ve beceriye dönüşmesine yardım eden aktif bir süreçtir. Bu nedenle klinik uygulamalar hemşirelik eğitiminin önemli bir kısmını oluşturmaktadır. Öğrenciler klinik uygulamalara çıktıkları sırada profesyonel hemşirelik becerisi eksikliğine dayalı yetersizlik hissi, hastalıkla ve ölümle karşılaşma, çocuk hastalara girişim uygulama, duygusal bağlanma, meslek grupları arasında profesyonel olmayan davranışları gözlemleme, hasta tedavilerine ilişkin yaşanan ikilemleri ve hastalardan kendi eğitimleri için yararlanıyor olmaları gibi birçok duygusal olarak onlara acı veren duygusal zorlanmaları deneyimlemektedir. ${ }^{1-4}$ Pourafzal ve ark. ${ }^{4}$ yaptıkları çalışmada hemşirelik öğrencilerinin klinik uygulamalarda algıladıkları stres düzeylerinin orta ve yüksek düzeyde olduğunu, Labrague ${ }^{5}$ ise hemşirelik öğrencilerinin klinik uygulama sırasında mutsuz, depresif, gergin ve endişeli olduklarını aynı zamanda da öğrencilerin deneyimledikleri olumsuz duyumlar karşısında tepki olarak duygusal reaksiyonlar gösterdiklerini belirtmiştir.

Yaşamın her anında deneyimlenen duygular, bilinçli bir çabadan ziyade kendiliğinden ortaya çıkan ve genellikle farklı fizyolojik değişikliklerin eşlik ettiği bilişsel bir durum olarak tanımlanır. Duygular olumlu ya da olumsuz, kısa süreli ya da uzun süreli ve çeşitli yoğunluk seviyelerinde deneyimlenmektedir. ${ }^{6,7}$ Duyguların problem çözme ve karar verme becerisi üzerinde etkisi olduğunun bilinmesiyle birlikte duyguların akademik performans üzerinde motivasyon, dikkat ve hafıza gibi bilişin her yönünü etkileyen kritik bir öneme sahip olduğu da yadsınamaz. $^{8-10}$ Öğrencilerin klinik ortamlarda deneyimlediği kendilerini iyi hissettiren duygular çoğu zaman yaratıcılık gibi öğrenmeyi destekleyen ve mesleklerine bağlılıklarını artıran bir etki yaratırken, hata yapma korkusu, yetersizlik gibi yoğun yaşanan ve düzenlenemeyen duyguların ise öğrencilerin dikkatini kendilerine yönlendirmelerine, odaklanma kapasitelerinin olumsuz etkilenmesine neden olarak öğrenmeyi zorlaştırdığı belirtilmektedir. ${ }^{11,12}$ Thompson ${ }^{13}$ duygu düzenlemeyi bireylerin amaçlar1na ulaşmada duygusal tepkilerini izleme, düzenleme, değerlendirme ve değiştirmeden sorumlu içsel ve dışsal süreçler olarak tanımlamıştır. Duygusal zorlanma yaşayan öğrencilerin hafiza, dikkat, konsantrasyon, karar verme ve sorun çözme becerilerinin olumsuz etkileneceği buna ek olarak yapılan araştır- malarda düzenlenemeyen duyguların çeşitli ruhsal sorunları meydana getireceği de belirtilmektedir. ${ }^{14-16}$ $\mathrm{Bu}$ amaçla hemşire eğitimcilere öğrencilerin duygusal zorlanmalarını anlamaları ve duygusal zorlanmalarını düzenlemelerine yardımcı olma konusunda önemli roller düşmektedir. Hemşirelik öğrencileri üzerinde yapılan çalışmalarda çoğunlukla stres, stresle başa çıkma, anksiyete üzerine yoğunlaşılırken, klinik deneyim sırasında yaşanan duygusal zorlanmalar, duygusal zorlanmaları etkileyen faktörler ve duygu düzenleme çalışmalarına daha az odaklanıldığ belirlenmiştir.

$\mathrm{Bu}$ nedenle klinik deneyim yaşayan hemşirelik öğrencilerinin yaşadıkları duygusal zorlanmaların nedenlerini ve duygu düzenleme güçlüğünü etkileyen faktörleri belirlemek amacıyla bu çalışma yapılmıştir.

\section{MATERYAL VE METOT}

Helsinki Bildirgesi ilkelerine bağlı olarak gerçekleştirilen bu araştırmaya başlamadan önce Trakya Üniversitesinin Bilimsel Araştırmalar Etik Kurul'u tarafindan araştırma onaylandı (Tarih: 23.12.2019, karar no: 22/09). Sağlık Bilimleri Fakültesi Dekanlığından kurumsal izin alınmıştır. Ayrıca çalışmaya katılan öğrencilere çalışma hakkında bilgi verilerek sözlü onamları alınmıştır.

Araştırmanın Evreni ve Örneklemi: Araştırmanın evrenini 2019-2020 öğretim y1lında bir devlet üniversitesinin hemşirelik bölümünde öğrenim gören ve klinik deneyim yaşayan ikinci, üçüncü ve dördüncü sınıfta olan 498 öğrenci oluşturmuştur. Veriler Aralık 2019-Ocak 2020 tarihleri arasında toplanmıştır. Araştırmaya katılmaya gönüllü olan 342 öğrenci araştırmanın örneklemini oluşturmuştur. Evrenin \% 68,67'ne ulaşılmıştır.

Veri Toplama Araçları: Veriler, Anket Formu ve Duygu Düzenleme Güçlüğü Ölçeği-Kısa Form kullanılarak topland1.

Anket Formu: Araştırmacilar tarafindan oluşturulan anket formunda, öğrencilerin kişisel özelliklerini içeren (yaş, cinsiyet, sınıf, yaşanılan yer vb.) ve duygusal zorlanmayla ilgili olmak üzere toplamda 11 soru bulunmaktadir.

Duygu Düzenleme Güçlüğü Ölçeği-Kısa Form: Gratz ve Roemer $^{17}$ tarafindan duygu düzenleme güçlüklerini belirlemek amaciyla geliştirilmiş, Yiğit ve Guzey Yiğit ${ }^{18}$ tarafından 2017 yılında Türkçeye uyarlanarak geçerlik ve güvenirlik çalışması yapılmıştır. Bireylerin duygu düzenlemede yaşadığı genel güçlüğü değerlendiren bu ölçeğin kısa formu 16 
maddeden oluşmakta ve 5'li Likert tipi ölçek kullanılarak değerlendirilmektedir. Ölçeğin, 1. ve 2. madde "açıklık" (duygusal tepkilerin anlaşılmaması), 9. 10. ve 13. madde "kabul etmeme" (tepkilerin kabul edilmemesi), 5.6 . 12.14 . ve 16. madde "stratejiler" (duygu düzenleme stratejilerine sinırlı erişim), 4. 8. ve 11. madde "dürtü” (olumsuz duygularda dürtülerin kontrolünde güçlük) ve 3. 7. ve 15 . madde "amaçlar" (olumsuz duygular deneyimlerken amaç odaklı davranışlarda bulunmada güçlük yaşama) olmak üzere 5 alt boyutu bulunmaktadır. Ölçeğin iç tutarlılık katsayısı 0,92 olarak bulunmuştur. $\mathrm{Bu}$ araştırmada ölçek genelinin iç tutarlılık katsayısı 0,92 bulunurken, açıklık alt boyutu için 0,85 , kabul etmeme 0,77 , stratejiler 0,84 , dürtü 0,83 ve amaçlar alt boyutu için 0,80 olarak hesaplanmıştır.

Verilerin Analizi ve Yorumu: Araştırmadan elde edilen veriler, SPSS (Statistical Package for Social Science for Windows) 22,0 yazılım programı kullanılarak değerlendirilmiştir. Ölçeklerin geçerlik ve güvenirliğini belirlemede iç tutarlılık için Cronbach alfa analizi, öğrencilerin nominal ve ordinal değişkenlei için frekans, yüzde, ortalama, minimum, maksimum, standart sapma, ortanca değerler, normallik analizleri, Spearman korelasyonu ve araştırmanın bağımsız değişkenlerinin ölçek toplam puanı ile karşılaştırılmasında veriler normal dağılmadığı için Mann Whitney U testi ile Kruskal Wallis testi kullanılmıştır. Tüm bulgularda anlamlılık sınır değeri 0,05 olarak kabul edilmiştir.

\section{BULGULAR}

Öğrencilerin yaş ortalaması $20,66 \pm 1,53, \% 80,1$ ' $\mathrm{i}$ kadın ( $\mathrm{n}=318), \% 39,8$ 'inin ikinci sınıfta okuduğu, \% 5,1'inin yaşamının çoğunluğunu Marmara bölgesinde geçirdiği, \%80,1'inin çekirdek ailede yaşadığı, \% 51,2'sinin duygu ve düşüncelerini ifade edebildiği demokratik bir aileye sahip olduğu, \%18,1'inin fiziksel, \%10,2'sinin ruhsal bir problemi olduğu, \% 21,3'ünün psikolojik bir destek aldığı, \%55,6'sının yaşamında önemli bir olayla karşılaştığı belirlendi (Tablo 1).

Tablo 2'de, klinik deneyim sırasında öğrencilerin ilk sırada profesyonel hemşirelik becerisi eksikliğine dayalı yetersizlik hissi ve ikincil olarak ise meslek grupları arasında profesyonel olmayan davranışları gözlemlediklerinde duygusal zorlanma yaşadıkları saptandi.

Tablo 3'te araştırmaya katılan öğrencilerin Duygu Düzenleme Güçlüğü Ölçeği toplam puan ortalaması $37,88 \pm 12,11$, alt boyutları puan ortalamalarının ise; Açıklık 4,76 $\pm 1,80$, Kabul etmeme 6,34 $\pm 2,78$, Strate-

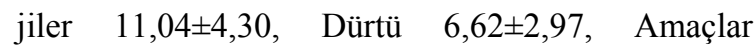
$9,10 \pm 3,00$ olarak bulundu.

Tablo 4'te öğrencilerin tanımlayıcı özelliklerine göre duygu düzenleme ölçeği ve alt boyut puan ortancalarının dağılımı görülmektedir. Erkek öğrencilerin kadın öğrencilere göre dürtü alt ölçeği puanları daha yüksektir $(p<0,05)$. Dördüncü sınıf öğrencilerinin ikinci ve üçüncü sınıf öğrencilerine göre duygu düzenleme ölçeği toplam puan ortancalarının daha düşük olduğu belirlendi fakat oluşan fark istatistiksel olarak anlamlı bulunmadı ( $\mathrm{p}>0,05)$ Demokratik tutuma sahip aile yaklaşım tarzı olan öğrencilerin diğer üç aile tutumuna göre dürtü, strateji, amaçlar ve toplam ölçek puan ortancalarının daha düşük olduğu saptandı $(p<0,05)$. İç Anadolu bölgesinde yaşamını geçiren öğrencilerin diğer bölgelerde yaşayan öğrencilere göre toplam ölçek puan ortancalarının daha yüksek olduğu belirlendi fakat oluşan bu fark istatiksel açıdan anlamlı bulunmadı ( $p>0,05)$. Parçalanmış ailede yaşayan öğrencilerin çekirdek ve geniş ailede yaşayan öğrencilere göre toplam ölçek puanlarının daha yüksek olduğu fakat bu farkın anlamlı olmadığı saptandı $(p>0,05)$. Fiziksel hastalığı bulunan öğrencilerin hastalığ strateji, amaçlar ve toplam ölçek puan ortancalarının daha yüksek olduğu belirlendi $(p<0,05)$. Öğrencilerden ruhsal hastalığı bulunanların ruhsal hastalığ bulunmayanlara göre kabul etmeme, strateji ve toplam ölçek puan ortancalarının daha yüksek olduğu görüldü $(\mathrm{p}<0,05)$. Psikolojik destek alan öğrencilerin destek almayan öğrencilere göre duygu düzenleme güçlügü ölçeği ve tüm alt boyut puan ortalamalar1nın daha yüksek olduğu belirlendi $(p<0,05)$. Yaşamında önemli bir olay deneyimleyen öğrencilerin diğer öğrencilere göre dürtü alt ölçeği ve tüm ölçek puanının daha yüksek olduğu saptandı $(\mathrm{p}<0,05)$.

\section{TARTIŞMA VE SONUÇ}

Hemşirelik stresli ve tükenmişliği fazla olan mesleklerin başında gelmektedir. Hemşirelik öğrencileri profesyonel olarak çalışmaya başladıklarında yoğun ve zorlayıcı duygularla karşı karşıya kalacaklardır. $\mathrm{Bu}$ nedenle öğrencilik yaşantısında hasta ve ailenin sorununu saptamada ve hemşirelik bakımını uygulamada yaşanan duygusal zorlanmaları fark etme ve duygu düzenlemeyi öğrenmeleri beklenmektedir. ${ }^{19}$ Yapılan araştırmalarda hemşirelerin duygularını bilinçli olarak fark etmediği ve çeşitli adaptif, maladaptif duygu düzenleme stratejilerini kullandıkları saptanmıştır. ${ }^{20,21} \mathrm{Bu}$ çalışma klinik deneyim yaşayan hemşirelik öğrencilerinin duygu düzenleme güçlüklerini belirlemek ve bazı tanımlayıcı özellik- 
lerle karşılaştırmak amacıyla yapılmıştır.

Hemşirelik öğrencilerinin klinik deneyim öncesi yaşadıkları yoğun duygular literatürde ele alınmışken, klinik deneyim sırasında yaşadıkları duygusal zorlanmalar hakkında literatürde daha az bilgiye rastlanılmıştır. ${ }^{3,22}$ Araştırmada öğrencilerin klinik ortamda en fazla meslek grupları arasında profesyonel olmayan davranışları gördüklerinde ve profesyonel hemşirelik becerisi eksikliğine bağlı yetersizlik hissi deneyimlediklerinde duygusal zorlanma yaşadıkları göze çarpmaktadır. Araştırma bulguları bir bütün olarak ele alındığında, klinik deneyim yaşayan hemşirelik bölümü öğrencilerinin duygusal tepkilerini fark edemediği, kabul edemediği, olumsuz duygu deneyimlerinde amaçlı davranışlarda bulunmada, dürtülerini kontrol etmede ve acı veren duyguları deneyimlerken duyguların etkilerinden kurtulmada duygu düzenlemelerinin yeteri kadar etkili olmadığ 1 saptanmıştır. Öyle ki literatürdeki araştırmalarla benzerlik göstermektedir. ${ }^{3,23,24}$

Öğrencilerin cinsiyetlerine göre duygu düzenleme güçlüğü ölçeği puan ortancalarında erkek öğrencilerin kadın öğrencilerine göre dürtü alt boyutunun daha yüksek puan aldığı saptanmıştır. Duygu düzenlenmesinde dürtü kontrolü son derece önemlidir. Dürtüsellik olumsuz sonuçların olacağını tahmin etmeden gerçekleștirilen kontrolsüz davranışlarda bulunma olarak tanımlanabilir. ${ }^{25}$ Literatürde nörobiyolojik mekanizmalar arasındaki etkileşim vurgulanarak dürtüsellik ile cinsiyet hormonlarının özellikle testesteronla olan ilişkisi belirtilmektedir. ${ }^{26}$ Aynı zamanda Schreiber ve ark. ${ }^{27}$ yaptıkları çalışmada da genel olarak duygu düzensizliği ile dürtüsellik arasındaki ilişkiyi vurgulamaktadır. Çalışmamızda da erkeklerin duygu düzenleme zorluklarının daha fazla olduğu görülmektedir. $\mathrm{Bu}$ nedenle çalışma sonucumuz literatürü destekler niteliktedir.

Ailenin çocuklara yaklaşım tarzları çocukların duygusal gelişimini etkilemektedir. Morris ve ark. ${ }^{28}$ ebeveynlerin duygusal desteğinin duygu koçluğunun ve ortak stratejilerin kullanımının çocukların duygu düzenlemelerine yardımcı olduğunu belirtmektedir. Araştırmamızda da ailesinde demokratik yaklaşım tarzı olan öğrencilerin ilgisiz, koruyucu ve otoriter aile yaklaşım tarzlarına göre dürtü, strateji, amaçlar ve toplam ölçek puan ortancalarının daha düşük olduğu saptanmıştır. Araştırmamızın sonuçları literatürü destekler niteliktedir.

Fiziksel hastalığı bulunan öğrencilerin hastalığı olmayan öğrencilere göre strateji, amaçlar ve toplam ölçek puan ortancalarının daha yüksek olduğu saptanmıştır. Fiziksel hastalıklar psikolojik ve fizyolojik sorunları beraberinde getirir ve böylece hastalığa sahip bireyler daha fazla stres deneyimler. Stres bireylerin başa çıkmasını olumsuz etkileyerek duygu düzenlemede yetersizlikler ortaya çıkarmaktadır. Aynı zamanda duygu düzenlemesi yetersiz olan bireylerin riskli sağlık davranışları sonucunda fiziksel hastalık oluşumuna neden olacağı da belirtilmektedir. ${ }^{29} \mathrm{Bu}$ sonuç, fiziksel hastalığı bulunan öğrencilerin duygu düzenlemelerinde güçlük yaşayacağını ve duygu düzenleme güçlüğü bulunan öğrencilerinde fiziksel hastalıklarının artacağı şeklinde yorumlanabilir.

Araştırmamızın diğer bir anlamlı sonucu ise araştırmaya katılan öğrencilerden ruhsal hastalığı bulunanların ruhsal hastalığı bulunmayanlara göre kabul etmeme, strateji ve toplam ölçek puan ortancalarının aynı zamanda psikolojik destek alan öğrencilerin de destek almayan öğrencilere göre duygu düzenleme güçlüğü ölçeği ve tüm alt boyut puan ortancalarının daha yüksek olduğu bulunmuştur. Ruhsal hastalığ bulunan ya da psikolojik destek alan öğrencilerin günlük yaşamda psikososyal zorluklarla karşı karş1ya kaldıkları söylenebilir. Ruhsal hastalığa sahip bireylerin düşük işlevselliklerinin olması gibi durumlar duygusal tepkilerini kabullenmede zorlanmalarına ve duygu düzenleme stratejilerini sınırlı olarak kullanmalarına neden olacağını düşünülmektedir aynı zamanda depresif belirtiler gibi ruhsal sorunlarda da duygu düzenlemenin güçleştiği çalışmalarla desteklenmektedir. ${ }^{30}$ Sonuç literatürle paralellik göstermektedir.

Yaşamında önemli bir olay deneyimleyen öğrencilerin diğer öğrencilere göre dürtü alt ölçeği ve toplam ölçek puanının daha yüksek olduğu saptanmıştır. Duygusal acı yaşayan bireyler içsel yaşantılarını tolere edemedikleri düşünüldüğünde dürtülerin kontrolünde ve duygu düzenlemede güçlük yaşamalar1nın olağan olduğu düşünülmektedir.

Araştırmanın sonucunda hemşirelik öğrencilerinin klinik uygulamaları sırasında yoğun duygular deneyimledikleri ve bu duyguları nasıl düzenledikleri konusunda ise yeterli farkındalıklarının bulunmadığı belirlenmiştir. Hemşirelik öğrencilerinin klinik uygulamaları sırasında yaşadıkları duygusal zorlanmaların ortadan kaldırılması mümkün değilken yaşadıkları duygusal zorlanmaların farkına varabilmelerine, duygusal zorlanmalarının nedenleri belirlenerek duygu düzenleme stratejilerinin oluşturulmasına yardımcı olunabilir. Hemşirelik öğrencilerinin profesyonel olarak iş yaşamına başladıklarında hasta bakımı sırasında yaşadıkları duyguları fark ederek tanımlamada, verdikleri tepkilerin farkında olmala- 
rında ve sorunlar karşısında doğru kararlar alabilmelerinde öğrencilik döneminde duygu düzenleme becerilerini kazanmış olmaları gerektiği düşünülmektedir. Bu nedenle hemşirelik eğitimcilerinin, öğrencilerin duygu düzenleme becerilerinin geliştirilmesi için ders müfredatlarına öz farkındalık, duygusal zeka, duygusal farkındalık ve duygu düzenleme becerisi derslerini eklemelerinin ve öğrencilerin duygu düzenleme becerilerini geliştirmek için zor hastalarla yaşanan davranışsal sorunların yoğun olarak ele alındığı simülasyon programlarının geliştirilmesi ve kullanılmasının yararlı olacağı düşünülmektedir.

Etik Komite Onayı: Çalışmamız Trakya Üniversitesinin Bilimsel Araştırmalar Etik Kurul'u tarafından onayland1 (Tarih: 23.12.2019, karar no: 22/09).

Çıkar Çatışması: Yazarlar çıkar çatışması bildirmemektedir.

Yazar Katkıları: Fikir-NAS, ÇT, NA; Veri toplanması ve/veya işlemesi - NAS, ÇT, NA; Analiz ve/ veya yorum -NAS, ÇT, NA; Yazıyı yazan -NAS, NA, ÇT.

Hakem değerlendirmesi: Dış bağımsız.

\section{KAYNAKLAR}

1. Chan KL, So KW, Fong YT. Hong Kong baccalaureate nursing students' stress and their coping strategies in clinical practice. Journal of Professional Nursing. 2009;25:307-313. doi:10.1016/ j.profnurs.2009.01.018

2. Jamshidi N, Molazem Z, Sharif F, Torabizadeh C, Najafi Kalyani M. The challenges of nursing students in the clinical learning environment: A qualitative study. The Scientific World Journal. 2016;5:1-7. doi:10.1155/2016/1846178

3. Weurlander M, Lönn A, Seeberger A, Broberger E, Hult H, Wernerson A. How do medical and nursing students experience emotional challenges during clinical placements? International Journal of Medical Education. 2018;9:74-82. doi:10.5116/ijme.5a88.1f80

4. Pourafzal F, Seyedfatemi N, Inanloo M, Haghani H. Relationship between perceived stress with resilience among undergraduate nursing students. Hayat. 2013;19(1):41-52.

5. Labrague LJ. Stress, stressors, and stress responses of student nurses in a government nursing school. Health Sci J. 2013;7(4):424-435.

6. Denham SA, Bassett HH, Wyatt T. The socialization of emotional competence. In: Grusec, JE, ed Handbook of socialization: Theory and research. Guilford Press; 2007:614-637.
7. Gillespie SM, Beech AR. Theories of emotion regulation. In Boer DP, Beech $A R$, Ward $T$, Craig LA, Rettenberger M, Marshall LE. Eds. The Wiley handbook on the theories, assessment, and treatment of sexual offending. Wiley Blackwell; 2017:123-136.

8. Greenberg LS. Emotion-focused therapy: Coaching clients to work through their feelings. Washington; 2002.

9. Seli P, Wammes JD, Risko EF, Smilek D. On the relation between motivation and retention in educational contexts: the role of intentional and unintentional mind wandering. Psychon. Bull. Rev. 2016;23:1280-1287. doi:10.3758/s13423015-0979-0

10. Tyng CM, Amin HU, Saad MN, Malik AS. The influences of emotion on learning and memory. Frontiers in psychology. 2017;8:14541463. doi:10.3389/fpsyg.2017.01454

11.Hascher T. Learning and Emotion: perspectives for theory and research. European Educational Research Journal. 2010;9:13-28. doi:10.2304/ eerj.2010.9.1.13

12. Sarıtaş Atalar D, Atalay AA. Ergenlik döneminde duygu düzenleme ve ruh sağlığı: Anababanın ve mizacın rolü. Bildik, T, ed. Ergenlik dönemi ve ruhsal bozukluklar, Türkiye Klinikleri. Ankara; 2018:84-90.

13. Thompson RA. Emotion regulation: A theme in search of definition. Monogr. Soc. Res. Child Dev. 1994;59:25-52.

14. Amstadter A. Emotion regulation and anxiety disorders. Journal of anxiety disorders. 2018;22:211-221. doi:10.1016/j.janxdis.2007.02. 004

15. Berking M, Poppe C, Luhmann M, et al. Is the association between various emotion-regulation skills and mental health mediated by the ability to modify emotions? Results from two crosssectional studies. Journal of Behavior Therapy and Experimental Psychiatry. 2012;43:931-997. doi:10.1016/j.jbtep.2011.09.009

16. Joormann J, Stanton CH. Examining emotion regulation in depression: A review and future directions. Behaviour Research and Therapy. 2016;86:35-49. doi:10.1016/j.brat.2016.07.007

17. Gratz KL, Roemer L. Multidimensional assessment of emotion regulation and dysregulation: Development, factor structure, and initial validation of the Difficulties in Emotion Regulation Scale. J Psychopathol Behav Assess. 2004:26:4154. doi:10.1023/B:JOBA.0000007455.08539.94 
18. Yiğit İ, Guzey Yiğit M. Psychometric properties of Turkish version of difficulties in emotion regulation scale-brief form (DERS-16). Current Psychology. 2019;38:1503-1511. doi:10.1007/ s12144-017-9712-7

19. Blanco-Donoso LM, Garrosa E, Demerouti E, Moreno-Jiménez B. Job resources and recovery experiences to face difficulties in emotion regulation at work: A diary study among nurses. International Journal of Stress Management. 2017;24:107-134. doi:10.1037/str0000023

20. Hayward RM, Tuckey MR. Emotions in uniform: How nurses regulate emotion at work via emotional boundaries. Human Relations. $\begin{array}{lllllllllllllllll}2 & 0 & 1 & 1 & ; & 6 & 4 & : & 1 & 5 & 0 & 1 & - & 1 & 5 & 2 & 3\end{array}$. doi:10.1177/0018726711419539

21. Dubert CJ, Schumacher AM, Locker L, Gutierrez AP, Barnes VA. Mindfulness and emotion regulation among nursing students: Investigating the mediation effect of working memory capacity. Mindfulness. 2016;7:1061-1070. doi:10.1007/s12671-016-0544-6

22. Dwyer PA, Revell SMH. Preparing students for the emotional challenges of nursing: An integrative review. Journal of Nursing Education. 2014;54:7-12. doi:10.3928/01484834-2014122406

23. Evgin D, Çalışkan ZI, Caner N. Sağlık yüksekokulu hemşirelik bölümü öğrencilerinin klinik uygulama öncesi kaygı düzeyleri ve stresle başa çıkma tarzları. SDÜ Sağlık Bilimleri Dergisi. 2017;8(3):22-28. doi:10.22312/sdusbed.280540

24. Cha NH, Sok SR. Depression, self-esteem and anger expression patterns of Korean nursing students. International Council of Nurses. 2013;1:109-116. doi:10.1111/inr.12076

25. Moeller GF, Barratt ES, Dougherty DM, Schmitz JM, Swann AC. Psychiatric aspects of impulsivity. American Journal of Psychiatry. 2001;158 (11):1783-1793. doi:10.1176/appi.ajp.158. 11.1783

26. Agrawal J, Ludwig B, Roy B, Dwivedi Y. Chronic testosterone increases impulsivity and influences the transcriptional activity of the alpha -2a adrenergic receptor signaling pathway in rat brain. Molecular Neurobiology. 2019;56(6):4061 -4071. doi:10.1007/s12035-018-1350-Z

27. Schreiber LR, Grant JE, Odlaug BL. Emotion regulation and impulsivity in young adults. Journal of Psychiatric Research. 2012;46 (5):651-658. doi:10.1016/j.jpsychires. 2012 . 02.005
28. Morris AS, Criss MM, Silk JS, Houltberg BJ. The impact of parenting on emotion regulation during childhood and adolescence. Child Development Perspectives. 2017;11:233-238. doi:10.1111/cdep.12238

29. Appleton AA, Kubzansky LD. Emotion regulation and cardiovascular disease risk. In Gross JJ, ed. Handbook of emotion regulation. The Guilford Press; 2014:596-613.

30. Sağlam F, Aslan E, Hurşitoğlu O. Bipolar bozukluk hastalarının ve birinci derece yakınlarının duygu düzenleme güçlükleri. Anadolu Psikiyatri Dergisi. 2020;21(1):30-36. doi:10.5455/ apd.36087 
Tablo 1. Hemşirelik öğrencilerinin tanımlayıcı özellikleri (N=342).

\begin{tabular}{|c|c|c|c|}
\hline \multicolumn{2}{|l|}{ Tanıtıcı Özellikler } & \multicolumn{2}{|c|}{$\overline{\mathbf{X}} \pm \mathbf{S S}$} \\
\hline \multirow{2}{*}{ Yaş } & & \multicolumn{2}{|c|}{$20,66 \pm 1,53(\min : 18-\max : 33)$} \\
\hline & & $\mathbf{N}$ & $\%$ \\
\hline \multirow{5}{*}{ Cinsiyet } & Kadın & 274 & 80,1 \\
\hline & Erkek & 68 & 19,9 \\
\hline & 2. $\sin 1 f$ & 136 & 39,8 \\
\hline & 3. sinif & 105 & 30,7 \\
\hline & 4. $\sin 1 f$ & 101 & 29,5 \\
\hline \multirow{8}{*}{ Yaşamını geçirdiği bölge } & Marmara & 257 & 75,1 \\
\hline & Karadeniz & 9 & 2,6 \\
\hline & Ege & 16 & 4,7 \\
\hline & İç Anadolu & 4 & 1,2 \\
\hline & Akdeniz & 9 & 2,6 \\
\hline & Doğu Anadolu & 7 & 2,0 \\
\hline & Güneydoğu Anadolu & 13 & 3,8 \\
\hline & Yurtd1ş1 & 27 & 7,9 \\
\hline \multirow{3}{*}{ Aile Tipi } & Çekirdek & 274 & 80,1 \\
\hline & Geniş & 51 & 14,9 \\
\hline & Parçalanmış & 17 & 5,0 \\
\hline \multirow{4}{*}{ Ailenin yaklaşım tarzı } & İlgisiz & 24 & 7,0 \\
\hline & Koruyucu & 131 & 38,3 \\
\hline & Otoriter & 12 & 3,75 \\
\hline & Demokratik & 175 & 51,2 \\
\hline \multirow{2}{*}{ Fiziksel hastalık durumu } & Evet & 62 & 18,1 \\
\hline & Hayır & 280 & 81,9 \\
\hline \multirow{2}{*}{ Ruhsal hastalık durumu } & Evet & 35 & 10,2 \\
\hline & Hayır & 307 & 89,8 \\
\hline \multirow{2}{*}{ Psikolojik destek alma durumu } & Evet & 73 & 21,3 \\
\hline & Hayır & 269 & 78,7 \\
\hline \multirow{2}{*}{ Yaşamında önemli bir olay deneyimleme } & Evet & 190 & 55,6 \\
\hline & Hayır & 152 & 44,4 \\
\hline \multirow{2}{*}{ Duygu eğitimine katılma durumu } & Evet & 49 & 14,3 \\
\hline & Hayır & 293 & 85,7 \\
\hline
\end{tabular}

$\overline{\mathbf{X}}=$ Ortalama; $\mathrm{SS}=$ Standart Sapma. 
Tablo 2. Hemşirelik öğrencilerinin klinik deneyimlerdeki duygusal zorlanmalarının dağılımı.

\begin{tabular}{|l|c|c|}
\hline Öğrencilerin Duygusal Zorlanmaları & $\mathbf{n}^{*}$ & $\mathbf{\%}$ \\
\hline Hastayla tanışmada hastanın istemsiz olması & 144 & 42,1 \\
\hline Hastalarla iletişim kurmak & 40 & 11,7 \\
\hline Ağır hastalık ve ölümle karşılaşma & 117 & 34,2 \\
\hline Hastalara duygusal bağlanma & 107 & 31,3 \\
\hline Hastanın tedaviye aniden tepki göstermesi & 125 & 36,5 \\
\hline Profesyonel hemşirelik becerisi eksikliğine dayalı yetersizlik hissi & 175 & 51,2 \\
\hline Tedavide ikilem (uygulama farklılıkları) yaşama & 102 & 29,8 \\
\hline Meslek grupları arasında profesyonel olmayan davranışları gözlemleme & 201 & 58,8 \\
\hline Hastalardan eğitimim için yararlanıyor olma & 120 & 35,1 \\
\hline
\end{tabular}

*: Birden fazla yanıt verildiği için n sayısı katlanmıştır. 
Tablo 3. Hemşirelik öğrencilerinin duygu düzenleme güçlüğü ölçeği ve alt boyut puan ortalamalarının dağılımı $(\mathrm{N}=342)$.

\begin{tabular}{|l|c|c|c|c|}
\hline Ölçek Alt Boyutları & Medyan (Q1-Q3) & Mod & $\overline{\mathbf{X}} \pm$ SS & $\begin{array}{c}\text { Ölçekten Alınabilecek } \\
\text { En Düşük ve En Yüksek Puan }\end{array}$ \\
\hline Açıklık & $4,00(4,00-6,00)$ & 4,00 & $4,76 \pm 1,80$ & $2-10$ \\
\hline Kabul etmeme & $6,00(4,00-8,00)$ & 4,00 & $6,34 \pm 2,78$ & $3-15$ \\
\hline Stratejiler & $10,00(8,00-14,00)$ & 8,00 & $11,04 \pm 4,30$ & $5-25$ \\
\hline Dürtü & $6,00(4,00-8,00)$ & 6,00 & $6,62 \pm 2,97$ & $3-15$ \\
\hline Amaçlar & $9,00(7,00-11,00)$ & 6,00 & $9,10 \pm 3,00$ & $3-15$ \\
\hline Toplam & $\mathbf{3 6 , 0 0}(\mathbf{2 9 , 0 0 - 4 5 , 0 0 )}$ & $\mathbf{3 6 , 0 0}$ & $\mathbf{3 7 , 8 8} \pm \mathbf{1 2 , 1 1}$ & $\mathbf{1 6 - 8 0}$ \\
\hline
\end{tabular}


Tablo 4. Hemşirelik öğrencilerinin duygu düzenleme güçlüğü ölçeği ve alt boyut puan ortancalarının tanımlayıcı özelliklere göre dağılımı $(\mathrm{N}=342)$.

\begin{tabular}{|c|c|c|c|c|c|c|}
\hline \multirow{3}{*}{$\begin{array}{l}\text { Tanıtıcı Özel- } \\
\text { likler }\end{array}$} & \multicolumn{6}{|c|}{ Duygu Düzenleme Güçlüğü Ölçeği ve Alt Boyutları } \\
\hline & Açıklık & Dürtü & Kabul etmeme & Stratejiler & Amaçlar & Toplam ölçek \\
\hline & $\begin{array}{l}\text { Medyan } \\
\text { (Q1-Q3) }\end{array}$ & $\begin{array}{l}\text { Medyan } \\
\text { (Q1-Q3) }\end{array}$ & $\begin{array}{l}\text { Medyan } \\
\text { (Q1-Q3) }\end{array}$ & $\begin{array}{l}\text { Medyan } \\
\text { (Q1-Q3) }\end{array}$ & $\begin{array}{l}\text { Medyan } \\
\text { (Q1-Q3) }\end{array}$ & $\begin{array}{l}\text { Medyan } \\
\text { (Q1-Q3) }\end{array}$ \\
\hline \multicolumn{7}{|l|}{ Cinsiyet } \\
\hline Kadın & $4,00(4,00-5,20)$ & $6,00(4,00-8,00)$ & $6,00(4,00-8,00)$ & $10,00(8,00-13,00)$ & $9,00(7,00-12,00)$ & $36,00(29,00-44,25)$ \\
\hline Erkek & $4,00(4,00-6,00)$ & $7,00(5,00-9,00)$ & $6,00(4,00-9,00)$ & $10,50(7,25-15,00)$ & $8,00(6,00-11,00)$ & $36,00(29,25-47,75)$ \\
\hline Test/p & $Z=9,404 \mathrm{p}=0,89$ & $\begin{array}{c}Z=10,995 \\
\mathbf{p}=\mathbf{0 , 0 2} *\end{array}$ & $\mathrm{Z}=10,165 \mathrm{p}=0,24$ & $Z=9,670 p=0,62$ & $\mathrm{Z}=8,003 \mathrm{p}=0,07$ & $Z=9,701 \mathrm{p}=0,59$ \\
\hline \multicolumn{7}{|l|}{ Sinıf } \\
\hline 2. sinif & $4,00(4,00-6,00)$ & $6,00(4,00-8,00)$ & $6,00(4,00-8,00)$ & $11,00(8,00-14,00)$ & $9,00(7,00-12,00)$ & $36,00(20,00-44,75)$ \\
\hline 3. sinif & $4,00(4,00-6,00)$ & $6,00(4,00-8,50)$ & $6,00(5,00-8,00)$ & $11,00(8,00-13,50)$ & $9,00(7,00-11,00)$ & $37,00(30,00-47,50)$ \\
\hline 4. $\sin 1 f$ & $4,00(4,00-5,00)$ & $6,00(4,50-8,00)$ & $5,00(4,00-7,00)$ & $10,00(7,00-14,00)$ & $9,00(6,00-11,00)$ & $34,00(28,00-43,00)$ \\
\hline Test/p & $X^{2}=6,69 p=0,30$ & $\mathrm{X}^{2}=0,36 \mathrm{p}=0,83$ & $X^{2}=3,29 p=0,19$ & $\mathrm{X}^{2}=1,62 \mathrm{p}=0,44$ & $\mathrm{X}^{2}=1,179 \mathrm{p}=0,55$ & $\mathrm{X}^{2}=2,40 \mathrm{p}=0,30$ \\
\hline \multicolumn{7}{|c|}{ Yașamını geçirdiği bölge } \\
\hline Marmara & $\begin{array}{l}4,00(4,00- \\
5,00)\end{array}$ & $6,00(4,00-8,00)$ & $6,00(4,00-8,00)$ & $10,00(8,00-14,00)$ & $9,00(7,00-11,00)$ & $36,00(29,00-43,00)$ \\
\hline Karadeniz & $\begin{array}{c}4,00(3,50- \\
5,50)\end{array}$ & $6,00(4,50-11,00)$ & $6,00(3,00-9,00)$ & $11,00(6,00-13,50)$ & $8,00(6,00-12,50)$ & $39,00(28,50-44,50)$ \\
\hline Ege & $4,00(4,00-6,00)$ & $7,00(5,25-9,00)$ & $5,00(4,00-8,00)$ & $10,00(8,25-14,00)$ & $10,50(6,25-12,75)$ & $35,50(31,00-47,50)$ \\
\hline İç Anadolu & $5,00(4,00-7,50)$ & $6,00(3,00-6,00)$ & $8,50(3,75-11,75)$ & $13,50(10,00-17,00)$ & $10,00(7,25-14,25)$ & $44,00(33,50-59,00)$ \\
\hline Akdeniz & $5,00(4,00-6,00)$ & $6,00(4,50-8,50)$ & $6,00(5,00-8,50)$ & $8,00(7,00-11,00)$ & $7,00(6,50-9,50)$ & $36,00(30,50-39,50)$ \\
\hline Doğu AD. & $4,00(4,00-5,00)$ & $6,00(4,00-7,00)$ & $6,00(5,00-9,00)$ & $9,00(6,00-11,00)$ & $6,00(6,00-9,00)$ & $31,00(26,00-41,00)$ \\
\hline $\begin{array}{l}\text { Güneydoğu } \\
\mathrm{AD} \text {. }\end{array}$ & $4,00(3,50-7,00)$ & $8,00(6,00-12,50)$ & $6,00(4,50-12,00)$ & $10,00(6,50-15,00)$ & $10,00(7,00-12,00)$ & $36,00(32,00-55,50)$ \\
\hline Yurtdıș1 & $4,00(4,00-6,00)$ & $7,00(5,00-9,00)$ & $6,00(5,00-8,00)$ & $12,00(8,00-15,00)$ & $9,00(6,00-11,00)$ & $36,00(30,00-48,00)$ \\
\hline Test/p & $\mathrm{X}^{2}=2,64 \mathrm{p}=0,91$ & $\mathrm{X}^{2}=12,95 \mathrm{p}=0,07$ & $\mathrm{X}^{2}=2,03 \mathrm{p}=0,95$ & $\mathrm{X}^{2}=4,93 \mathrm{p}=0,66$ & $\mathrm{X}^{2}=8,31 \mathrm{p}=0,30$ & $X^{2}=4,43 p=0,72$ \\
\hline \multicolumn{7}{|l|}{ Aile tipi } \\
\hline Çekirdek & $4,00(4,00-5,25)$ & $6,00(4,00-8,00)$ & $6,00(4,00-8,00)$ & $10,00(8,00-13,00)$ & $9,00(7,00-11,00)$ & $36,00(29,00-44,00)$ \\
\hline Geniş & $4,00(4,00-5,00)$ & $6,00(4,00-9,00)$ & $6,00(4,00-8,00)$ & $10,00(8,00-14,00)$ & $9,00(6,00-11,00)$ & $36,00(30,00-45,00)$ \\
\hline Parçalanmış & $5,00(4,00-7,00)$ & $6,00(4,50-10,50)$ & $5,00(3,50-8,50)$ & $12,00(6,00-17,00)$ & $9,00(6,00-12,00)$ & $39,00(27,00-53,50)$ \\
\hline Test/p & $\mathrm{X}^{2}=1,38 \mathrm{p}=0,50$ & $\mathrm{X}^{2}=0,80 \mathrm{p}=0,66$ & $\mathrm{X}^{2}=0,52 \mathrm{p}=0,76$ & $\mathrm{X}^{2}=0,67 \mathrm{p}=0,71$ & $\mathrm{X}^{2}=0,42 \mathrm{p}=0,97$ & $\mathrm{X}^{2}=0,42 \mathrm{p}=0,80$ \\
\hline \multicolumn{7}{|c|}{ Ailenin yaklașım tarzı } \\
\hline İlgisiz & $4,50(4,00-7,00)$ & $5,00(4,00-6,00)$ & $8,00(5,00-11,75)$ & $12,50(9,25-18,00)$ & $11,50(8,00-14,75)$ & $44,00(31,50-63,50)$ \\
\hline Koruyucu & $4,00(4,00-5,00)$ & $8,00(6,25-10,75)$ & $6,00(4,00-8,00)$ & $10,00(8,00-14,00)$ & $9,00(7,00-11,00)$ & $36,00(30,00-46,00)$ \\
\hline Otoriter & $4,00(4,00-8,50)$ & $8,00(6,25-10,75)$ & $6,50(5,25-10,00)$ & $13,50(11,25-15,50)$ & $9,50(8,25-11,00)$ & $43,00(36,50-51,50)$ \\
\hline Demokratik & $4,00(4,00-5,00)$ & $4,00(4,00-6,00)$ & $6,00(4,00-8,00)$ & $10,00(7,00-13,00)$ & $9,00(6,00-11,00)$ & $35,00(28,00-43,00)$ \\
\hline Test/p & $\mathrm{X}^{2}=4,84 \mathrm{p}=0,18$ & $X^{2}=13,03 \mathbf{p}=\mathbf{0 , 0 0 *}$ & $\mathrm{X}^{2}=7,32 \mathrm{p}=0,62$ & $\mathrm{X}^{2}=14,34 \mathrm{p}=0,00 *$ & $\mathrm{X}^{2}=8,11 \mathbf{p}=\mathbf{0 , 0 4 *}$ & $X^{2}=12,35 \mathbf{p}=\mathbf{0 , 0 0 *}$ \\
\hline \multicolumn{7}{|c|}{ Fiziksel hastalık durumu } \\
\hline Evet & $4,00(4,00-6,00)$ & $7,00(4,75-10,00)$ & $7,00(4,00-9,00)$ & $12,00(9,75-15,00)$ & $10,00(7,00-12,00)$ & $41,50(33,75-49,00)$ \\
\hline Hayır & $4,00(4,00-5,00)$ & $6,00(4,00-8,00)$ & $6,00(4,00-8,00)$ & $10,00(7,00-13,00)$ & $9,00(6,00-11,00)$ & $11,00(11,00-14,00)$ \\
\hline Test/p & $\mathrm{Z}=7,610 \mathrm{p}=0,10$ & $\mathrm{Z}=7,367 \mathrm{p}=0,06$ & $\mathrm{Z}=7,783 \mathrm{p}=0,19$ & $\mathrm{Z}=6,432 \mathbf{p}=\mathbf{0 , 0 0 *}$ & $Z=6,784 \mathbf{p}=\mathbf{0 , 0 0 *}$ & $Z=6,417 \mathbf{p}=\mathbf{0 , 0 0 *}$ \\
\hline \multicolumn{7}{|c|}{ Ruhsal hastalık durumu } \\
\hline Evet & $5,00(4,00-6,00)$ & $7,00(5,00-10,00)$ & $7,00(5,00-10,00)$ & $13,00(10,00-17,00)$ & $9,00(7,00-13,00)$ & $40,00(33,00-54,00)$ \\
\hline Hayır & $4,00(4,00-5,00)$ & $6,00(4,00-8,00)$ & $6,00(4,00-8,00)$ & $10,00(7,00-13,00)$ & $9,00(7,00-11,00)$ & $36,00(29,00-44,00)$ \\
\hline Test/p & $\mathrm{Z}=4,553 \mathrm{p}=0,11$ & $\mathrm{Z}=4,478 \mathrm{p}=0,10$ & $\mathrm{Z}=4,027 \mathbf{p}=\mathbf{0 , 0 1 *}$ & $\mathrm{Z}=3,559 \mathbf{p}=\mathbf{0 , 0 0 *}$ & $\mathrm{Z}=4,734 \mathrm{p}=0,24$ & $\mathrm{Z}=4,041 \mathbf{p}=\mathbf{0 , 0 1 *}$ \\
\hline \multicolumn{7}{|c|}{ Psikolojik destek alma durumu } \\
\hline Evet & $5,00(4,00-6,00)$ & $7,00(5,00-9,00)$ & $7,00(5,00-9,00)$ & $12,00(9,50-15,00)$ & $10,00(7,00-12,00)$ & $40,00(34,00-51,00)$ \\
\hline Hayır & $4,00(4,00-5,00)$ & $6,00(4,00-8,00)$ & $6,00(4,00-8,00)$ & $10,00(7,00-13,00)$ & $9,00(6,00-11,00)$ & $35,00(29,00-43,50)$ \\
\hline Test/p & $\begin{array}{l}Z=7,768 \\
\mathbf{p}=\mathbf{0 , 0 0 *}\end{array}$ & $Z=8,014 \mathbf{p}=\mathbf{0 , 0 1 *}$ & $Z=7,860 \mathbf{p}=\mathbf{0 , 0 0 *}$ & $Z=7,107 \mathbf{p}=\mathbf{0 , 0 0 *}$ & $\mathrm{Z}=7,781 \mathbf{p}=\mathbf{0 , 0 0 *}$ & $Z=7,172 \mathbf{p}=\mathbf{0 , 0 0 *}$ \\
\hline \multicolumn{7}{|c|}{ Yaşamında önemli bir olay deneyimleme } \\
\hline Evet & $4,00(4,00-5,25)$ & $6,00(5,00-9,00)$ & $6,00(4,00-8,00)$ & $11,00(8,00-14,25)$ & $9,00(7,00-12,00)$ & $37,00(30,75-47,00)$ \\
\hline Hayır & $4,00(4,00-6,00)$ & $6,00(4,00-8,00)$ & $6,00(4,00-7,75)$ & $10,00(7,00-13,00)$ & $9,00(6,00-11,00)$ & $34,00(28,00-43,00)$ \\
\hline Test/p & $\begin{array}{c}Z=13,664 \\
p=0,36\end{array}$ & $\begin{array}{c}Z=12,500 \\
\mathbf{p}=\mathbf{0 , 0 3} *\end{array}$ & $Z=13,516 \mathrm{p}=0,35$ & $Z=12,777 p=0,06$ & $\mathrm{Z}=12,811 \mathrm{p}=0,07$ & $Z=12,605 \mathbf{p}=\mathbf{0 , 0 4 *}$ \\
\hline
\end{tabular}

